realignment in library and university budgeting. The tired old phrases of the library being the heart of the university have to be backed up with funding, or hardening of the arteries and cardiac arrest are not too far off.

Personally, I believe that percentage funding issues should become a matter of professional ethics. If we are as good and as professional as we say we are, then we have to be willing to back it up in terms of where we will allow ourselves to work, and under what conditions. Our national standards will be credible only when every librarian applying for every job brings them up before they are hired. After all, in the words of sage Yoda from The Return of the Jedi, 'there is no 'try,' there is only what we "do."”

\title{
Onsite observations of
}

\section{automated library systems}

\author{
By Evelyn Lyons \\ Interlibrary Loan \& Online Services Librarian \\ Millersville University
}

\section{A checklist to aid the automation observer.}

$\mathbf{T}$ place manual circulation services and card catalogs with integrated systems continues to gather momentum. The library automation industry is approaching maturity and smaller academic libraries with fewer resources at their command are coming into the automation market. In this instance, as in so many other areas of rapid technological development, it is not disadvantageous to be among the late arrivals.

Economic historians have observed that there is an advantage to relative backwardness. The innovators struggled to design the first examples of these very complex systems and, when successful, were able to enjoy the fruits of their labor and their substantial risk-taking. Librarians today do not have to suffer the same pain of creation nor sustain the same awesome costs. It is now possible to approach a vendor of a developed syetem and receive an estimate of the ultimate price of an installation.
Today's automation marketplace, while not exactly stable, presents the smaller academic library with the possibility of making a rational choice among cornpeting systems. Ganser Library at Millersville University in Pennsylvania, a member of a 14-unit state higher education system with a student body of around 6,000, recently began its evaluation of the available library automation systems.

The library faculty had formed an automation committee, and many of the 14 professional librarians began to read widely in the literature on automation. Some took courses at schools of library science. Nearly everyone visited vendors' exhibits at major conferences. Whenever possible we sought out libraries in our region that have installed automated systems.

In the fall of 1986 I was granted a sabbatical leave by Millersville University to study automation in representative libraries. The rationale for the study was that neither visits to vendors at con- 

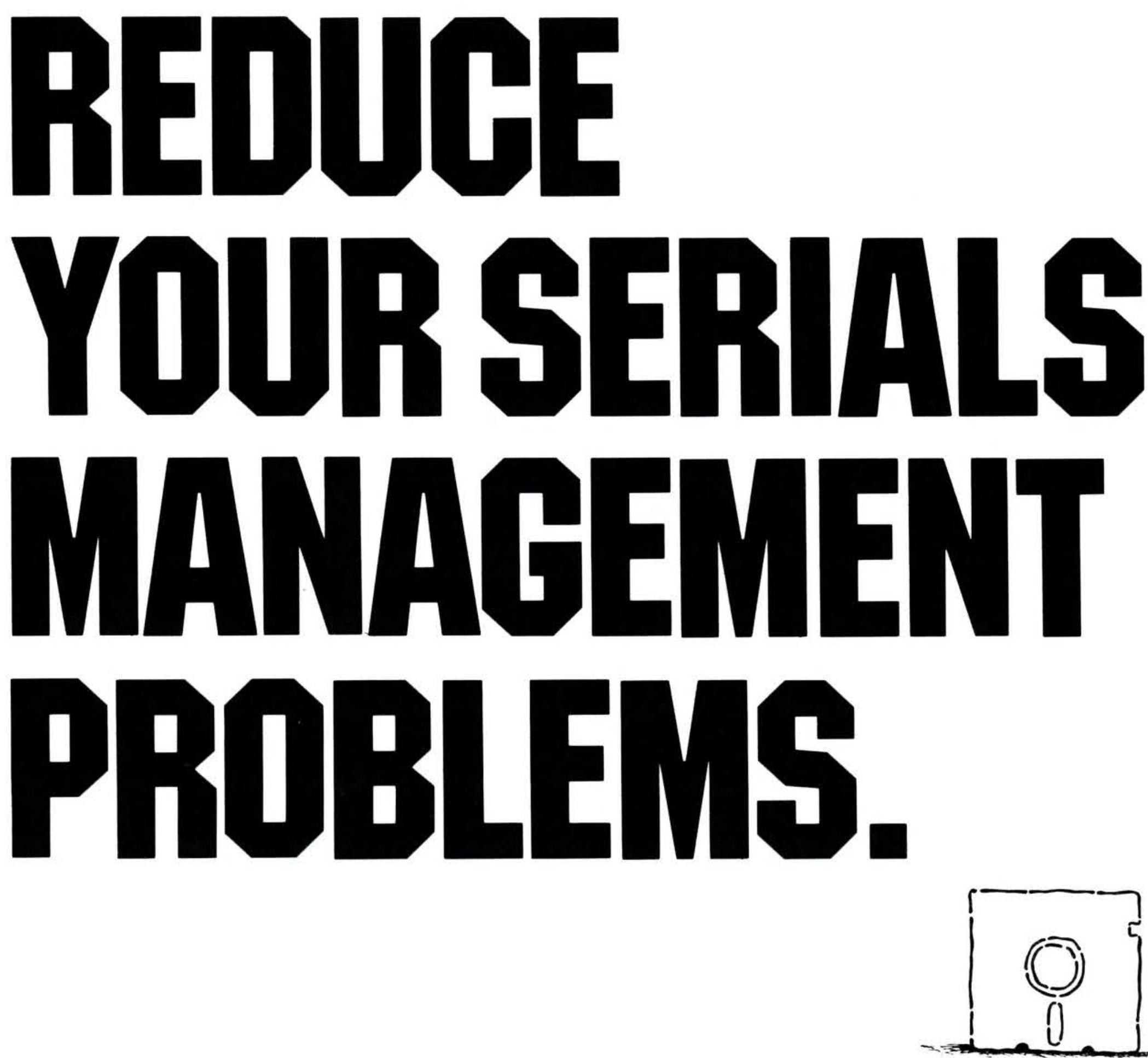

Now you can use a few square inches of counter space to support a full serials management system.

Remo, the first microcomputer based software package handles the full range of serials management functions.

Remo offers automated claiming, routing management, analysis and user generated custom reports in a stand alone or network configuration.

Remo is the modern cost effective way to convert a time consuming manual process into a fast and easy check-in operation with full automated support. In the event of questions, an answer is only a phone call away on our toll free hot line.

Find out how Remo can help you reduce your serials management problems. Write for further information or call us at (800) 221-3306.

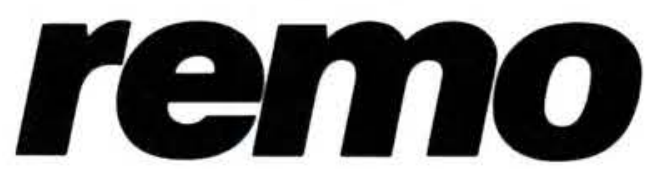

READMORE 
ferences nor reading brochures, specifications, and evaluative literature in the professional journals reveals the actual texture of life in an automated library environment. For that, one needs to meet the people who went through the planning and installation phases and who now work with the systems daily. This seemed the best way to gain a solid reality-based understanding of automation as it actually exists in libraries.

Because it is so easy to get caught up in the narrative of the always helpful (and usually enthusiastic) systems librarians one encounters, I wanted to go forth armed with a device for structuring an interview. I began to jot down all the questions I might want to ask. As I read journal articles pointing out new pitfalls for the would-be automator, I inserted questions that reflected my newly acquired concerns. Finally I sought the input of my colleagues, who came up with some of the most pertinent questions. From this effort an effective survey instrument developed.

In actual practice I rarely marched through the questionnaire item by item. Conversations do not flow that way. However, by referring to my checklist periodically, I found that I could insert my questions into the discussion. I was less likely to forget to cover important points. Since the actual interviews with the librarians in charge of systems never fell into neat outline form, I usually just took frantic notes. When I returned to my study and reviewed my notes, I was able to fill in the blanks on my form. Notes that might have become incomprehensible in time were easily captured. Because I had a structure for my data, information acquired at a number of diverse libraries in interviews that varied in form and style was organized so that interlibrary comparisons could be made.

From all the data certain patterns emerged. I began to develop a clearer idea of the features that Ganser Library ought to insist on when the time arrives for an RFP. Some of the pitfalls looked more threatening than others. We should also have a better idea of what to avoid.

So far my colleagues have heard one person's view of several automation systems. When our library comes closer to the actual selection of a system, we may arrange some on-site demonstrations so that the entire staff-professional and support personnel-will be able to make their own observations of the competing systems. The survey instrument that I developed could thus be of assistance to the rest of the staff.

To extend my assumption about the usefulness of this instrument I am suggesting that other libraries in search of an automated system might find it a helpful guide in their investigations. There are, of course, other ways to use the questionnaire. A researcher could adapt it for the purpose of selfadministration. It was, however, designed to be kept firmly in the hands of the interviewer who would use discretion in posing questions, using the flow of the discussion and and style of the interviewee as a guide. As an aid to memory and a device for organizing notes, it was of great value to me.

\section{A checklist on library automation}

\section{General information}

Institution name?

Enrollment?

Library name?

Contact?

Address?

Date of visit?

System name?

Installation date?

Software?

Hardware?

Number of records?

Number of terminals?

\section{Planning phase}

Did you use a consultant for a feasibility study?

For the design of an RFP?

For anything else?

What input and support did you receive from the administration?

From the faculty?

Was the professional library staff fully involved in the decision-making process?

Was the support staff?

Why did you choose this system?

\section{Vendor relationship}

How would you judge the quality of the personnel?

Are there persons knowledgeable about libraries?

Do they respond to queries in a timely fashion?

Are they available in an emergency?

How would you rate the vendor's staff in the performance of the following:

Response to the RFP?

Negotiation of contract?

Installation or system implementation?

Acceptance testing?

Staff training?

Documentation?

Ongoing support?

Does the vendor have a hotline?

Are there users' group meetings?

Is there a newsletter?

What are the annual maintenance costs?

Are software enhancements included?

Were there added costs above contract?

Any specific contract advice for my library? 


\section{System operation}

Do you have a designated systems person(s)?

What are his/her responsibilities?

Programming skills on staff?

Institutional support (computer center cooperation)?

Provisions for backup?

Provisions for downtime (i.e., micro program for circulation)?

How often and for how long is system down?

Is the problem usually with software? Hardware?

Security provisions: Levels of authorization to access and change data?

Provision for growth?

\section{The database}

Unitary database?

How are subsystems linked?

Retrospective conversion method?

What percent was conversion complete before system was installed?

Loading data from utility: Batch loading?

Electronic transfer in real time?

Authority control for author?

For subject headings?

Cross-reference capabilities?

Global replacement?

Did commercial company or utility produce authority files?

\section{Subsystems: Capabilities and features}

\section{A. Acquisitions}
Maintains vendor file?
Generates orders?
Possible to enter brief format into OPAC?
Order status transmitted to OPAC immediately?
Received (in process) status?
Claiming?
Fund accounting?
Report features?

B. Cataloging

\section{Scandinaviana}

The 78th Annual Meeting of the Society for the Advancement of Scandinavian Study will be held at the University of Oregon, Eugene, April 28-30, 1988. Anyone wishing to present a paper in history or the social sciences should contact Steven Koblik, Department of History, Pomona College, Claremont, CA 91711. All others should write to Virpi Zuck, Department of Germanic Languages and Literatures, University of Oregon, Eugene, OR 97403. The deadline for submitting a paper proposal is December 10, 1987. All conference participants must be paid-up members of SASS.
Transfer of bibliographic records from utility?

Creation of record: Uses utility? Catalogs on inhouse system?

Type of barcodes?

How are they generated?

Automated label printing?

Item records: How does system handle?

Subject headings: When do they appear in cata$\log$ ?

\section{Serials control}

Separate system or part of acquisitions?

Does system link online with serials vendor?

Are records linked to bibliographic record?

Does system support abbreviated records?

Describe access points.

Describe record content.

Describe check-in procedure.

Describe claiming.

Does system print claim notices?

Is there provision for bindery control?

Does the report function print holding list?

By subject?

Fund accounting and reports?

Does system generate orders?

D. Online public access catalog

Describe screen(s).

Menu and/or command driven?

Are help screens clear?

Optional quick search for experienced users?

Estimate response time.

Describe data elements in displayed record.

Describe access points.

Advanced searching techniques: Keywords? Boolean?

Does the system permit browsing?

Does the OPAC immediately reflect orders? Circulation? Check-in of serial items?

Are there queuing problems at OPAC?

How was number of terminals determined?

Do you have ports for dial access? Who may use?

Is there a local area network?

E. Circulation control

Is circulation fully integrated with the bibliographic database?

Can item records be created on the fly?

Can barcoding be accomplished on the fly?

How is the borrower's file created? Tape transfer?

Observe and estimate time for check-out and return.

Describe the following processes:

Overdue notices.

Recalls and holds.

Trapping delinquent patrons.

Assigning patron circulation status.

Updating patron information at check-out.

How does the system handle snags?

Is there a program for course reserves?

Ask the contact person, "What would you do differently if you had to do it again?" 

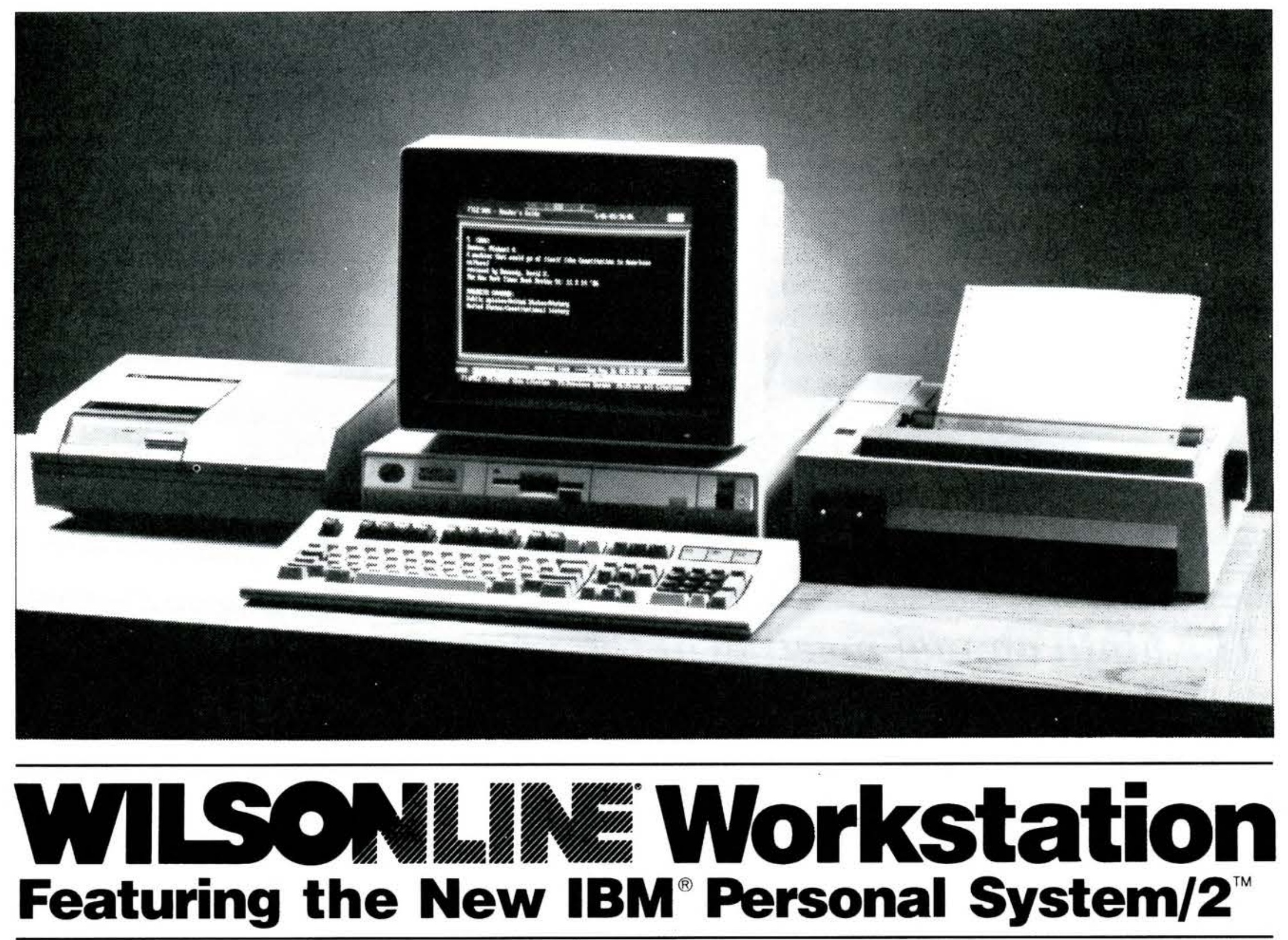

If you need computer hardware that will accommodate information retrieval systems as well as administrative tasks, from a reliable vendor, at the right price, the WILSONLINE Workstation is the answer.

\section{Computer Hardware for Tomorrow's Library}

Designed to accommodate WILSONDISC ${ }^{\mathrm{TM}}$, WILSONLINE ${ }^{\circledR}$, and WILSEARCH ${ }^{\circledR}$-the CD and online retrieval services that comprise the WILSONLINE Information System, the Workstation includes the new IBM Personal System/2 Model 30 computer-one of the best price performers on the market.

\section{Wilson Authorized IBM ${ }^{\circledR}$ Dealer}

Wilson's participation as an authorized IBM Value-Added dealer guarantees high-quality reasonably-priced equipment, and offers you a convenient, trusted source of supply.

\section{The WILSONLINE Workstation Consists of \\ - IBM Personal System $/ 2^{\text {TM }}$ Model 30 \\ - IBM Color Display 8512 Monitor \\ - IBM Proprinter ${ }^{\mathrm{TM}}$ II \\ - Philips CM 100 CD Player \\ - Hayes Smartmodem 1200B with Smartcom II Software \\ - DOS 3.3 Software}

Free Installation and a Full-Year Warranty Included in the price of a complete Workstation are on-site installation and training and a full year of IBM on-site maintenance or component replacement.

\section{Priced to Meet Your Library's Budget}

The WILSONLINE Workstation is available at $\$ 4,695$. You can also purchase the Philips CM 100 CD Player separately for $\$ 865$.

\section{To Order Call Toll-Free:} 1-800-367-6770

In New York State call 1-800-462-6060; in Canada call collect 212-588-8400.

\section{f THE H.W. WILSON COMPANY

